\title{
O CINEMA MODERNO SEGUNDO PASOLINI
}

\author{
Ismail Xavier*
}

Resumo: O artigo tece comentários sobre Pier Paolo Pasolini como térico do cinema e focaliza, em particular, a concepşão que o cineasta elaborou do cinema moderno em seus textos dos anos 60, especialmente em "Observaçōes sobre o plano-sequiência" e "Cinema de poesia". Săo al discutidas noções como a de "cinema de poesia" e "subjetiva indireta livre", bem como a oposição entre plano-seqüéncia e montagem, quando esta se apresenta, na formulação de Pasolini, como metafora da morte.

Palavras-chave: cinema moderno, teoria do cinema, critica.

a) o empirismo herético.

Tal como a intervenção de Pasolini em outros setores da vida cultural e política, sua teoria do cinema tem sido palco de renovada polêmica. No contexto da semiologia francesa dos anos 60 (à qual podemos anexar Umberto Eco), foi criticada pela imprecisão dos termos e pela "ingenuidade" presente em sua concepção do nexo indissolúvel existente entre imagem cinematográfica e real. Mais recentemente, Gilles Deleuze - enfático na defesa de Pasolini - não poupou Christian Metz e seus seguidores de ironias, e incluiu o cineasta italiano na tradição dos lúcidos pensadores que não aderiram ao projeto teórico que terminou por reduzir a sucessão das imagens na tela a algo equivalente a um enunciado lingüístico. Não cabe entrar, neste breve texto, no debate sobre as questões de método que assombram a "semiologia da realidade" de Pasolini; basta lembrar o quanto, dentro da investigação mais ampla e geral de uma teoria da imagem contemporânea, seus ensaios permanecem como referência nas discussões estéticas, dado que seu espaço de imprecisão encontrou larga compensação na agudeza de seus insights e na sua capacidade de tratar as questões candentes da teoria de maneira articulada à sua intervenção como ideólogo: a "semiologia da realidade" compôs um vasto programa de desmascaramento dos signos característicos da nova sociedade de consumo na Itália, sinais impressos na feição, nos gestos, na roupa

- Professor do Curso de Cinema da Escola de Comunicações e Artes, USP. 
XAVIER, Ismail. O cinema moderno segundo Pasolini.

e na fala, principalmente dos jovens, dados de um processo que Pasolini observou criticamente ${ }^{1}$

Meu texto se atém a noções que estão mais claramente expostas em dois dos seus ensaios sobre cinema: "O cinema de poesia"(1965) e "Observações sobre o plano-seqüência" (1967). Eles permitem resumir o percurso de Pasolini na avaliação do cinema moderno dos anos 60, percurso no qual o cineasta mobilizou a sua reflexão sobre a linguagem e a narrativa, marcando a originalidade de sua visão diante do conceito de "cinema moderno" herdado de André Bazin ou formulado por teóricos como Noël Burch. Tal como no caso destas duas figuras-chave do contexto francês, a preocupação de Pasolini era uma descrição formal-estilística capaz de distinguir o moderno do clássico. Na observação de traços como o plano-seqüência, a marca autoralsubjetiva ou o comportamento "mais solto", mais ousado, da cámara nos filmes dos novos cineastas, a diferença de sua teoria proveio da base lingüístico-literária de sua reflexão, toda centrada na questão da narrativa, não na questão do específico fílmico. Assim, ele pôde desenvolver um terceiro caminho. Este, de um lado, se mostrou distinto da proclamação realista de um Bazin: a vocação do cinema para a intuição de essências do real e a conseqüente superioridade do estilo moderno (primado do plano-seqüência, da ambigüidade, das fatias de vida respeitadas em sua duração), sobre o clássico ( primado da montagem, do controle - veja isto, depois aquilo -, da segmentação, do discurso fechado que impóe sentidos). De outro lado, se mostrou istinto da opção pela vanguarda no estilo underground feita por Noël Burch, onde a atenção se volta para a chamada "dialética das formas", para o cinema como arte plástica dotada de uma temporalidade apta a se organizar com um rigor semelhante ao da música, especialmente em pesquisas contemporâneas como a do serialismo.

Para Pasolini, o cinema traz o mundo para dentro de si mas este não se põe como substância transparente que o olhar atravessa em busca do sentido; constitui, ao contrário, um tecido de linguagens (da açāo, do corpo - aquela rede de sinais que cabe à "semiologia da realidade" decodificar). O mundo, desde o início, se dá como uma linguagem a decifrar, e ser moderno não implica num gesto de recusa da montagem em nome do real em duracão na tela. É nítida, por exemplo, sua oposição à experiência limite de Andy Warhol, com seus filmes feitos de planos-seqüências a observar a repetição

1 Ver os ensaios reunidos no livro Os jovens infelizes (São Paulo, Brasiliense, 1990), organizado por Michel Lahud. 
do gesto banal, a inação ou espaço vazio. Mas é também nítido que, embora as operações de montagem marquem a presença de uma subjetividade ordenadora, tal presença não deve, para Pasolini, dissolver uma "impregnação de mundo" muito própria à técnica do cinema como "escrita do real" (traço da prosa do mundo impresso na película); daí sua resistência ao que considera uma exacerbação subjetivista encontrada em algumas tendências mais deconstrutivas do cinema moderno, seja no underground americano ou no cinema de autor europeu. Entre estes pólos - radicalismo do plano-seqüência ou voluntarismo de uma montagem que se quer intransitiva, alheia ao mundo - ele vai construir sua teoria do moderno para explicar o cinema com que se julga mais afinado, guardadas as diferenças que o separam dos cineastas que servem de ilustração para seu argumento: Antonioni, Bertolucci, Godard, Glauber. Tal como o artista, o teórico Pasolini "decepciona"2.

Os dois ensaios sobre cinema aqui em pauta foram publicados no livro Empirismo herege que, como disse Giuseppe Zigaina, traz uma espécie de resumo do pensamento do autor, sendo ponto de intersecção entre literatura, arte e religião, caixa de ressonância de toda a sua obra poética ${ }^{3}$ Heresia, etimologicamente,se liga à noção de "escolha" e ganha, face a ortodoxias religiosas, a conotação de escolha própria, feita sem a presença do guia (Igreja, Estado, Partido). Há em Pasolini determinado empirismo, no sentido de pensar sempre a composição estética como algo derivado do real, da experiência, produto da imaginação onde é central a referência ao mundo e o engajamento nele; no entanto, traço marcante da heresia, tal empirismo não se confunde com o senso comum naturalista, não requer uma postura da arte-documento, nem se atém aos cânones do realismo próprios à estética dos intelectuais PCI, partido de que Pasolini foi membro na juventude e com que polemizou ao longo da vida. Seu empirismo é um corpo a corpo com o real, vontade de intervenção a cada milímetro de suas interações com a sociedade presente, mas é, acima de tudo, ação e discurso pelos quais o intelectual-artista reivindica a superioridade do seu juízo perante as "igrejas", reserva a si

2 Assim como o ato de inventar( sempre escandaloso) é perda "masoquista" de algo de certo, desejo de se contradizer, de infringir os códigos, o gesto teórico de Pasolini se desenvolve neste terreno de repetiçōes aparentes (a de Bazin, por exemplo), de inscriçōes heréticas em disciplinas cientificas (a semiologia, por exemplo), de torneios que causam surpresa, decepcionam o leitor, lembrando que este precisa refinar sua leitura.

3 Para os dois textos de Pasolini, tomo como referência a edição francesa, L'expérience hérétique - langue et cinéma, Paris, Payot,. 1976; para os comentários de Giuseppe Zigaina, ver o seu livro Pasollnt et la nort, Paris, Editions Ramsay, 1990. 
XAVIER, Ismail. O cinema moderno segundo Pasolini.

as escolhas: dos combates, do estilo de comportamento, do gênero de cinema, das modalidades de relação com o passado, das condições da própria morte.

Pasolini não separou arte e vida. Ancorado na concepção do real como linguagem, foi herético porque tal identidade não a pensou nos termos de um espelhamento puramente lógico - homologia de sistemas, encaixe de peças descarnadas - mas a pensou como combate pelo qual o artista compromete, instalando no terreno da luta, toda a sua experiência, exigindo de si mesmo a coerência dos sinais que emite, pela presença corporal no mundo, pelo cinema que produz, pela "linguagem da ação"

A manutenção de um vínculo com o mundo requer uma semiologia que incorpora um horizonte mítico (o mundo como linguagem é aí espaço sagrado, união maior de cultura e natureza). De um lado, há a demanda incisiva de não se descolar do real, da experiência; de outro, real e experiência se concebem a partir de um recorte heterodoxo face à tradição empirista. Pasolini não se dobra à ciência natural, ao pragmatismo burguês, mantendo-se fiel a uma concepção do real monista, totalizante, que se afina a uma tradição de pensamento que não separa mundo e representação, ação e linguagem, natureza e cultura. Pressuposto um cosmo organizado, o sistema de Pasolini cria espaço para a vivência do trágico, a consciência do imperativo de escolha da morte ( contra o instinto de conservação), a dimensão dionisíaca do sacrifício do artista; este sacrifício é entendido não apenas, no limite, como morte inapelável, mas, antes, como pequena morte reiterada pelo artista em seu poder criativo de decepcionar, expor-se à execração na esfera pública. $O$ sentido do percurso do artista se apoia, então, nesta vivência integral; e permanece em aberto até o instante da morte, momento determinante que fecha as perspectivas, apontando o teor específico da experiência encerrada: é a morte que, enquanto corte final, gera o sentido, permite transformar a vida em um discurso de contornos definidos, vulnerável ao trabalho da interpretação.

b) o estatuto do plano-seqüência.

O homem se exprime pela ação e esta não ganha significado enquanto não se completa. Morrer é necessário para que adquiramos sentido (entremos no espaço da cultura e da história). A morte opera uma síntese rápida da vida e lhe envia uma luz retroativa, uma seleção de pontos, constrói atos míticos e morais fora do tempo. Opera, enfim, como a montagem no cinema. Este é o argumento central do artigo "Observações sobre o plano-seqüência", peçachave na explicitação desta analogia entre morte e montagem, feita a partir 
R. Italianística, Såo Paulo, ano I, n 1, p. 101-109, 1993.

do comentário sobre o estatuto das imagens que documentaram in loco o instante da morte de Kennedy, em 1963.

Na tela, a vida se reproduz num virtual plano-seqüência infinito. Demarcação inexorável, a montagem corta o fluxo contínuo da imagem em movimento (registro do andamento do mundo, em princípio, aberto) e transforma a combinação dos fragmentos em discurso. Ela mortifica, então, os registros, as tomadas de cena (cada qual um morceau de vie), para que a sucessão possa adquirir significado. Completando o círculo da analogia, a montagem se define como uma violência exercida sobre as imagens que opera como a morte no seio da vida: delimita, fecha os percursos. A vida é como um cinema ao natural, o infinito plano-seqüência, aberto, que o registro cinematográfico permite "fixar" (como a escrita congela a fala), mas retirando o que é registrado do fluxo, delimitando, numa postura que tem um qué de perverso, porque fetichista (isola, fragmenta, separa), porque sadomasoquista (violência, mutilação).

No cinema, espécie de real mortificado, pode-se observar com grande nitidez a "linguagem da ação", as formas de presença e intervenção no mundo, o tecido social que é necessário ler, criticamente. A linguagem da ação define um aspecto dessa "semiologia da realidade" Esta é uma leitura do mundo que se exerce, diante da imagem cinematográfica, enfrentando os mesmos desafios encontrados nas situações que somos obrigados a interpretar na vivência cotidiana: para Pasolini, a imagem de um evento, em cada plano do filme, transfere para si as propriedades visíveis da situação tal como a experimentaríamos na vida real; ou seja, os códigos que regem a nossa leitura do mundo social "a olho nu" estão também operando quando o observamos através da câmara (quando temos uma tomada em fluxo contínuo). A diferença se instaura, no cinema, pela montagem. Esta é operação não apenas necessária, mas também desejável pois, se mortifica, por outro lado doa sentido, instaura uma perspectiva. E é isto que deve fazer toda narrativa.

Para Pasolini, a função do artista é "dizer", intervir, não simplesmente deixar o mundo se confessar na tela. O plano-seqüência infinito é pura hipótese e guarda uma função "pedagógica" como um ponto virtual que realça o aspecto contingente, particular, das delimitações operadas no que temos de concreto: os filmes em sua particularidade, com seu ponto de vista, sua estratégia narrativa, sua forma peculiar de produzir sentido - ou seja, montar, retirar o momento vivido do fluxo contínuo para fazê-lo "falar" no cotejo com outros momentos, vivências. Apoiada na operação de montagem, e não no elogio de supostos poderes revelatórios do plano-seqüência, a semiologia do cinema de Pasolini se afasta do naturalismo ingênuo. Isto é o que sua leitura dos filmes modernos atesta com toda clareza. coerentemente, 
XAVI ER, Ismail. O cinema moderno segundo Pasolini.

é o que sua própria obra de cineasta põe em prática, afastada que está das ilusões da transparência: cada filme de Pasolini é invenção de um modo de narrar (montar) para produzir sentido, fazer um diagnóstico do presente, mesmo com aparência de falar sobre o passado. A cada passo, ele soube mobilizar as mediações esclarecedoras, compor a parábola que permite tocar nas feridas da sociedade afual. Ou seja, soube demonstrar que o discurso sobre o presente envolve cotejos com formas de vida do passado, vivências do sagrado hoje "fora de pauta" no espaço urbano das sociedades avançadas, codificações da vida e do mundo ainda presentes no mundo camponês ou nas sociedades do terceiro mundo que ele nunca deixou de tomar como referência. Cotejando, trazendo ao olhar os dados de experiências arcaicas em paralelo com o mundo high tech da atualidade, o cinema de Pasolini é discurso autoral, inscrição do sujeito no fluxo de imagens, afirmação da vontade de expor um ponto de vista. Não surpreende seja esta categoria - a do ponto de vista que preside a narrativa - a peça-chave de sua teoria do cinema moderno.

c. $o$ cinema de poesia

O universo em que se movem a teoria e a prática de Pasolini é o do cinema narrativo-dramático, terreno em que ele procura trabalhar a emergência do poético como uma dimensão derivada de duas operações que vê mutuamente associadas: a da invenção de linguagem pela qual o filme chama a atenção sobre si e a da montagem das estratégias de subjetivação da imagem. Quanto à primeira das operações, o cinema moderno está pleno de instâncias em que, ao contrário do que ocorria no filme clássico, a câmara se mostra, chama a atenção sobre si, o aparato do cinema se impõe à percepção como dado construtivo da mise-en-scène. Aqui, o poético corresponde àquela opacidade pela qual o meio de expressão se faz ver, exibe estruturas de outro modo inconscientes, privilegiando o que Roman Jakobson denominou "função poética" da linguagem. O peso de Jakobson na teoria do poético naquele momento é enorme e Pasolini está traduzindo, em sua própria linguagem, uma teoria do cinema moderno presente em outros críticos e teóricos. Sua originalidade se afirma no comentário à segunda das operações.

As estratégias de subjetivação (ou a dimensão lírico-subjetiva da imagem), ele deve encontrá-las num cinema narrativo marcado por uma convenção estilística que alcança maior afinidade com o poético do que a convenção que dominava o filme clássico (o cinema de prosa). Para tanto, Pasolini faz 
um duplo movimento. Primeiro, ele mostra como as operações próprias ao moderno (este colocar em evidéncia o próprio aparato) estão, em verdade, articuladas com uma exigéncia de expressão do mundo interior das personagens (caso de Antonioni, Bertolucci), de modo que a dimensão lírico-subjetiva se afirma dentro mesmo do processo narrativo. Em segundo lugar, ele apresenta a teoria geral desta nova articulação posta pelo cinema moderno a partir de um empréstimo fundamental: a da noção de discurso indireto livre presente na teoria do romance. Ou seja, o cinema de prosa, dado o seu ideal de transparência, não tinha uma convenção estilística, uma forma de usar os procedimentos, capaz de "subjetivar" decisivamente a narrativa, expressar o teor da experiência interior na forma cinematográfica. O cinema (moderno) de poesia criou tal convenção. Superou, então, o que, segundo Pasolini, a tradição privilegiou: a "língua de prosa", este discurso que o espetáculo de evasão consolidou ao mascarar, sob suas regras narrativas, o que ele chama de "elementos irracionais". Haveria uma violéncia neste processo pelo qual o que é mais próprio ao cinema - sua afinidade com o onírico, com os signos da comunicação-consigo-mesmo - estaria recalcado pela tradição. Recalque que não teria dado chance para que se vivesse com mais intensidade uma das contradições mais ricas do cinema: ser um desfile de imagens e sons que, impregnado de uma carga de objetividade (reprodução técnica da aparência externa), traz, simultaneamente, a marca dos processos mais profundos Pasolini diz "elementares" - da psique. Subjetivo e objetivo, no mesmo movimento, o cinema alcança, com o uso do estilo indireto livre, um patamar de criação onde o processo narrativo se torna mais complexo, representando um maior desafio ao espectador. Este deve estar atento ao modo pelo qual os procedimentos técnicos (montagem, movimentos de câmara) presentes na visualização do mundo objetivo, na verdade, oferecem o código de uma vivência interior, subjetiva.

Na literatura, o discurso indireto livre permite uma imersăo na vida interior da personagem (ou em seu estilo próprio de linguagem, de sensibilidade) sem uma sinalização clara do limiar da interiorização; ou seja, sem que se determine, com toda segurança, quando passamos da visão exterior, digamos objetiva, para a visão mediada pela vivência da personagem que tem sua maneira de ver, sentir e "dizer" a situação (o escritor engendra um estilo capaz de dar forma a esta vivência, mantendo-a mesclada com o relato mais objetivo de um narrador externo). Pasolini vé algo de semelhante quando os cineastas modernos se utilizam do comportamento idiossincrático da cámara para, na própria observação do mundo objetivo, sinalizar a vivência da 
XAVIER, Ismail. O cinema moderno segundo Pasolini.

personagem, seu estilo de olhar, sem que se estabeleca com clareza a fronteira entre o que é visão exterior e interior.

O filme clássico também dá conta de processos subjetivos mas sua tendência é marcá-los, emoldurá-los, como tal; separá-los, contrastá-los, didaticamente da "visão objetiva" que constitui a sua norma. A diferença do moderno está na ambigüidade do processo, na ausência de marca diferencial entre a "visão objetiva" e a visão da personagem. É o filme inteiro que afirma um certo estilo de olhar, uma certa reiteração formal no comportamento de câmara e na montagem, os quais se põem como uma senha para se ler a psicologia do protagonista.

Evocando o termo tradicional que define a imagem quando esta é produto do olhar da personagem (câmara subjetiva), Pasolini dá um nome especial ao estilo indireto livre cinematográfico: subjetiva indireta livre. Ou seja, durante o filme inteiro estaremos vivenciando uma instabilidade, uma oscilação entre objetivo e subjetivo, na qual o movimento próprio das coisas se mescla ao movimento de uma interioridade, um contaminando o outro com seu estilo. Isto possibilita ao espectador uma visão mais compreensiva, interna, da experiência da personagem e o obriga a um constante cotejo entre a imagem que lhe é dada e a noção que ele tem do mundo, já que o filme não afirma uma realidade estável que emoldure e explique os movimentos da personagem (este seria o estilo, por excelência, de Antonioni, Bertolucci ou Godard, guardadas as suas diferenças).

Na caracterização acima, toda a minha ênfase recaiu sobre a criação de um parametro formal que, pela estrutura do filme, se assinala como correlato a um estilo individual de percepção do mundo (caso das personagens burguesas dos cineastas citados). Aqui, a conseqüência da subjetiva indireta livre é gerar uma linguagem capaz de desnudar um tipo de neurose moderna através de um espelhamento, ou cotejo, entre o indivíduo-protagonista e a norma da sociedade. Quer dizer, a invenção estilístico-formal tem um correlato de tipo psicológico (um protocolo individual de vivência do mundo). Observando os filmes de Pasolini, vemos este esquema sofrer um deslocamento para produzir outro efeito: o tipo de experiência, mundo interior, que o discurso indireto livre põe como mediação para a percepção das coisas é a experiência, o estilo de percepção, de alguém que é portador de uma cultura estranha à da platéia. Tal portador está ali para afirmar uma diferença; representa uma alteridade, o confronto entre passado (mundo arcaico do mito, experiência da natureza própria ao camponês) e presente (sociedade burguesa técnico-urbana). Como resultado, a invenção estilístico-formal passa a ter um correlato de tipo 
R. Italianística, São Paulo, ano I, n² 1, p. 101-109, 1993.

antropológico (código cultural do Outro, referência a uma vivência coletiva do mundo).

Em suma, estamos, no cinema de Pasolini, às voltas com aquele mesmo gesto de mobilizar uma "visão interior" mediadora, com a ambigüidade que descrevi, com a instabilidade que daí resulta; no entanto, há uma diferença: o elemento mediador que força o cotejo, desafia a norma burguesa, é de natureza cultural, é vivência de outro tempo, de outra civilização ${ }^{4}$

Este é o mundo das parábolas de Pasolini, do recurso ao mito e à lenda como mediação para falar do presente; o cinema de poesia tipicamente moderno do empirismo herético, exercício muito peculiar de uma negacão do senso comum, da idéia de objetividade da cultura tecnocrático-burguesa. Cinema que volta as costas para os valores de produção da indústria e se põe como resistência a um estilo de vida que resulta da aceitação acrítica, eufórica, mistificante, da dinâmica atual da modernização. Para Pasolini, este é o dado sinistro da sociedade italiana dos anos 60 e 70: o avanço do "fascismo de consumo".

Abstract: The article comments on Pier Paolo Pasolini's film theory, focusing on his conception of Modern Cinema as developed in his texts written in the sixties, specially "The Sequence-Shot"and "Cinema of Poetry". Here one finds a discussion of specific notions like "cinema of poetry" and "free indirect subjective", as well as a discussion about Pasolini's idea of Editing as Death in its opposition to Life embodied in the Sequence-Shot.

Key-words: modern cinema, film theory, film criticism.

4 O mesmo tipo de cotejo, com a mobilização do olhar do Outro na caracterizaçāo de situaçōes históricas de conflito, $\boldsymbol{\epsilon}$ muito próprio ao cinema de Glauber Rocha. O cineasta brasileiro trabaIha a matriz da dominaçāo colonial para caracterizar um estado de coisas presente, faz conviver uma visão religiosa da experiência e uma visão materialista, ambas se contradizendo mas participando do mesmo movimento de compreensão dos acontecimentos. $O$ cineasta italiano, no seu artigo, se refere a Deus e o diabo, de passagem. E pode-se tomar Terra em transe como típica instância do discurso indireto livre nos termos do cinema moderno definido por Pasolini. Já se reiterou o comentário sobre as afinidades entre os dois cineastas, em termos de concepçāo, interesse, estilo, modo de intervençăo na cultura, vocação para o sacrificio pessoal nos moldes da tragédia. A identidade de estratégias nesse plano mais microscópico da narraçáo moderna é um dado estetico muito preciso que vem selar a aproximaçāo, sugerir estudos de estilo fundamentais para aprofundar a idéia que fazemos do cinema dos anos 60 . 